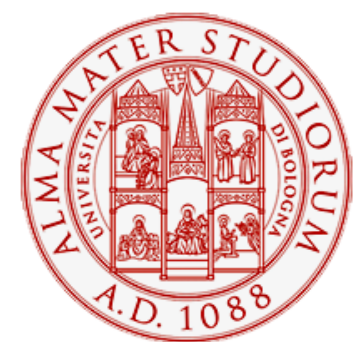

Alma Mater Studiorum - Università di Bologna DEPARTMENT OF ECONOMICS

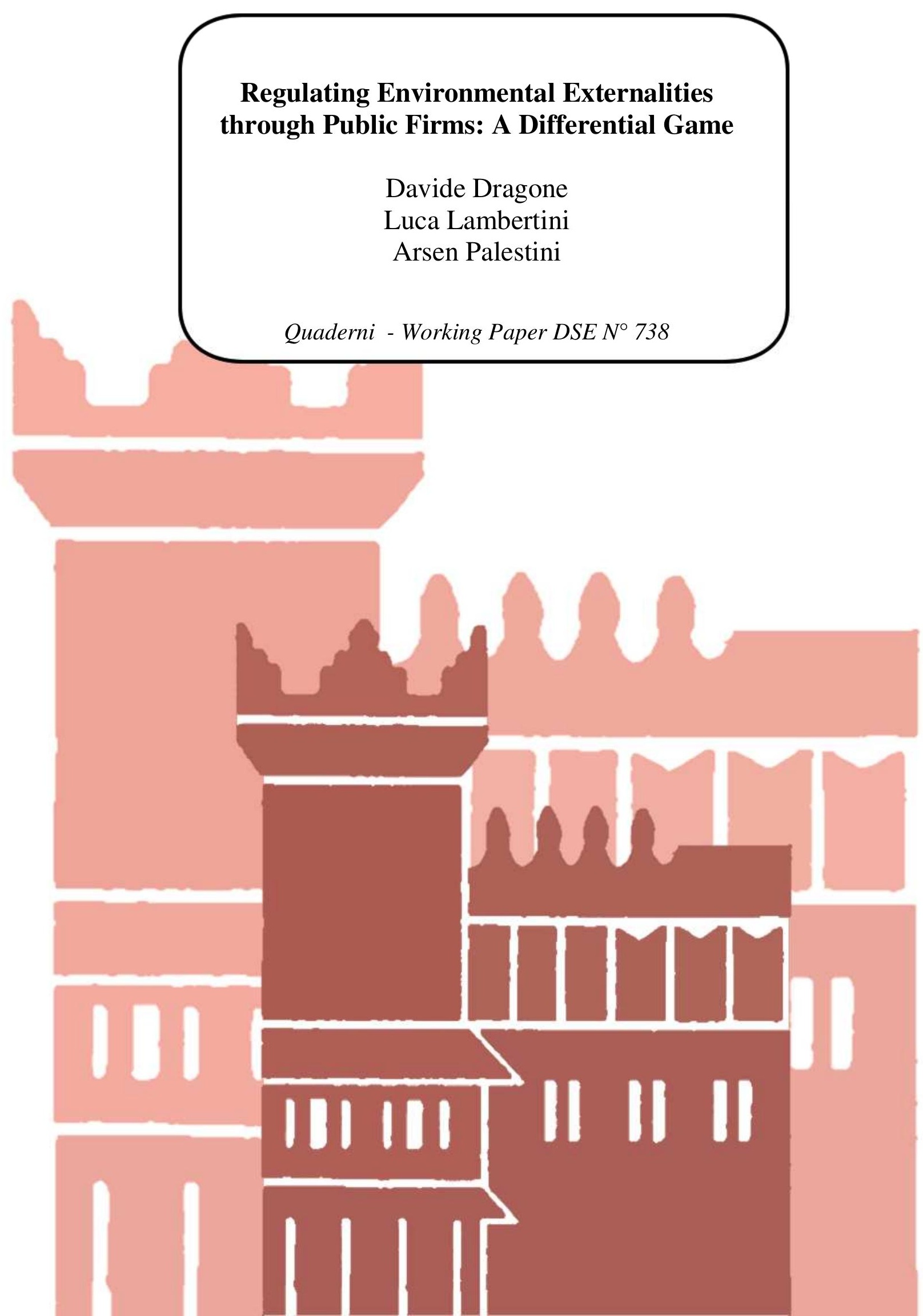




\title{
Regulating Environmental Externalities through Public Firms: A Differential Game*
}

\author{
Davide Dragone* Luca Lambertini*,§ Arsen Palestini\# \\ *Department of Economics, University of Bologna \\ Strada Maggiore 45, 40125 Bologna, Italy \\ fax +39-051-2092664; davide.dragone@unibo.it; luca.lambertini@unibo.it \\ $\S$ ENCORE, University of Amsterdam \\ Roeterstraat 11, WB1018 Amsterdam, The Netherlands \\ \# MEMOTEF, University of Roma "La Sapienza"
}

via del Castro Laurenziano 9, 00161 Roma, Italy; arsen.palestini@uniroma1.it

March 2, 2011

\begin{abstract}
We investigate the possibility of using public firms to regulate polluting emissions in a Cournot oligopoly where production takes place at constant returns to scale and entails a negative environmental externality. We model the problem as a differential game and investigate (i) the Cournot-Nash game among profit-seeking firms; (ii) the Markov Perfect Nash equilibrium under social planning, where the industry output is entirely controlled by a benevolent planner aiming at the maximisation of social welfare; and (iii) the Markov Perfect Nash equilibrium in a mixed setup where at least one firm is public, while the others remain profit-seeking agents. Our analysis identifies the conditions whereby having a mixed market as a regulatory instrument suffices to drive the industry to the same output, externality and social welfare as under planning, both along the optimal path and in steady state.
\end{abstract}

JEL codes: C73, D43, D62, L13, L32, Q50

Keywords: pollution, public firms, oligopoly, Markov perfect strategy.

${ }^{*}$ We thank Sergio Currarini, Martina Nardon, Tapio Palokangas, Paolo Vanin, Amos Zemel and the audience at the IFAC workshop CAO'09 (Jyväskylä), AMASES 2010 (Macerata), the Copenhagen Business School, the University of Lancaster and the University of Bologna for helpful comments and discussion. The usual disclaimer applies. 


\section{Introduction}

The regulation of polluting emissions is a relevant issue and is receiving an increasing amount of attention in the current agenda of policy makers. Several aspects of the matter have been analysed in detail. A relatively large subset of the existing contributions examines the existence and features of Pigouvian taxation aimed at reducing pollution, both in monopoly and oligopoly regimes (see Bergstrom et al., 1987; Karp and Livernois, 1992, 1994; Benchekroun and Long, 1998, 2002; and Tsur and Zemel, 2008, inter alia). Indirectly, Pigouvian taxation is also considered as a means for generating incentives towards R\&D investments in environmental-friendly technologies (to this regard, see Downing and White, 1986; Milliman and Prince, 1989; Damania, 1996; Chiou and Hu, 2001; and Tsur and Zemel, 2002, inter alia). The established approach common to all of these studies consists in outlining the social optimum, where a benevolent planner chooses a production plan for the firms in the industry so as to maximise social welfare, as a benchmark against which the performance of the profit-seeking firms has to be assessed. This produces corrective policy measures which affect the firms' incentives, and allows reproducing the same social welfare level associated with the first best.

Another stream of literature analyses the feasibility of tradeable pollution permits, which, however, may lead to the monopolization of the industry (see Newbery, 1990; and von der Fehr, 1993, inter alia). Monopolization, or at least some reduction in the degree of competition in an industry where negative environmental externalities play a major role, may not look as bad as one could imagine, as any output reduction entails two opposite effects: an increase in market price (which is, in principle, undesirable) and a decrease in the amount of polluting emissions (which is, instead, welcome). Accordingly, some degree of collusion and/or a wave of horizontal mergers increasing concentration may actually turn out to be welfare-improving (Lambertini and Mantovani, 2008).

A third line of research has shed light on the interplay between environmental externalities and growth or capital accumulation, with or without environmental taxation (Hartman and Kwon, 2005; Greiner, 2007; Bartz and Kelly, 2008; and Itaya, 2008, inter alia).

In the literature, the typical intervention to correct environmental externalities is aimed at modifying the agent's incentives to produce output and the associated amount of pollution. In general, this is done introducing tax schemes or subsidies 
(Benchekroun and Long, 1998, 2002). In this paper we target the same goal by focusing on a different tool: the creation of a mixed market where public firms aiming at the maximization of social welfare coexist with profit-seeking firms. ${ }^{1}$ To investigate this issue, we consider a dynamic model in continuous time and compare three alternative settings: the first is one where the industry is populated by $N$ profit-seeking firms playing a Cournot-Nash game; the second is the social planning case, where a benevolent dictator chooses industry output to maximise social welfare; the third is a mixed regime where at least one firm is public and maximizes social welfare, and the remaining firms are profit-seekers and maximize profits only.

Our first result is that the dynamic game among profit-seeking firms reproduces the same equilibrium strategies as the static counterpart. Consistent with the idea that profit-seeking firms neglect the external effect of their production, their output choices do not depend on the stock of pollution, nor on its evolution over time. On the contrary, the policy function of the social planner is decreasing in the stock of pollution. Comparing the two regimes, we find out that the planner may produce less or more than the Cournot oligopolists depending upon the tradeoff between the price effect and the externality effect associated to the output decision. We then consider a mixed market composed of profit-seeking firms and public firms. We show that the presence of public firms that internalize both the price and the externality effect associated to the market outcomes forces the private firms to internalize the amount of pollution produced by the industry. The regulator may therefore exploit the strategic interaction (whose essential features are summarised by the negative slope of the instantaneous best reply functions) to drive the industry output to the socially optimal level. Notably, the (stationary) Markov perfect strategies entail that the optimal industry output and the emission of pollution in the mixed market is exactly the same as under social planning, both along the optimal path and in steady state. This preludes to the possibility of introducing some public firm in the market to endogenously affect the behaviour of the remaining profit-seeking units, and drive the industry along the first best optimal path and steady state. Whether this alternative is desirable depends on the costs associated to the introduction of the public firms in the market. Public firms might indeed lack the appropriate market incentives to be as efficient as private firms. We acknowledge this issue

\footnotetext{
${ }^{1}$ The role of a public firm as a regulatory instrument in mixed oligopoly without environmental externalities has been lively debated. See Cremer, Marchand and Thisse $(1989,1991)$ and De Fraja and Delbono (1989, 1990).
} 
by allowing public firms to incur some X-inefficiency costs (see Leinbenstein, 1966, inter alia). We focus on the case where the social planner buys some profit-seeking firms at market prices and substitutes them with public firms. Even when both $\mathrm{X}$-inefficiencies and acquisition costs are taken into account, there exist conditions under which creating a mixed market is feasible and welfare improving.

The basic model is laid out in section 2 . The non-cooperative equilibrium between profit-maximizing firms is outlined in section 3. Section 4 contains the analysis of the social planning equilibrium. The two regimes are comparatively assessed in section 5 . In the section 6 the mixed setting is investigated to show the optimal behavior of private and public firms along the optimal path and in steady state, while in Section 7 the social desirability of the mixed market is assessed. Concluding remarks are in section 8 .

\section{The setup}

The basic structure of the model is borrowed from Benchekroun and Long (1998, 2002). Consider an oligopoly market over an infinite (continuous) time horizon, $t \in[0, \infty)$. Firms supply a homogeneous good, whose market demand function is

$$
p(t)=a-Q(t)
$$

at any time $t \in[0, \infty)$, with $a>0$ being a positive constant parameter measuring the reservation price and $Q(t)=\sum_{i=1}^{N} q_{i}(t)$ being the sum of all firms' output levels. Production takes place at constant returns to scale (CRS), with a marginal cost $c \in(0, a)$ constant and common to all firms, so that firm $i$ 's instantaneous cost function is $C_{i}(t)=c q_{i}(t)$. The production of the final output goes along with a negative environmental externality taking the form of a flow of polluting emissions $E(t)=Q(t)$. The stock of pollution $S(t) \in[0, \hat{S}]$ evolves over time according to the following dynamics:

$$
\dot{S}(t)=Q(t)-\delta S(t)
$$

where $\delta>0$ is the decay rate of the stock. The instantaneous external effect $\Theta(t)$ generated by pollution consists of two components generated by the flow $Q(t)$ and the stock $S(t)$, respectively:

$$
\Theta(t)=\varepsilon Q(t)+\gamma \frac{S^{2}(t)}{2},
$$


with $\varepsilon \in(0, a-c)$ and $\gamma>0$. Consumer surplus $C S(t)$ is measured by the area below the demand function and above market price $p(t)$, minus the externality $\Theta(t)$ :

$$
C S(t)=\frac{Q^{2}(t)}{2}-\varepsilon Q(t)-\gamma \frac{S^{2}(t)}{2} .
$$

It is worth noting that a contraction of output has ambiguous consequences over consumer surplus, due to the presence of a negative externality proportional to the output: on the one hand, shrinking output goes along with increasing market price, which is harmful; on the other hand, it entails reducing the environmental externality, which is desirable. The balance between these components will play a key role in the remainder of the analysis.

Social welfare, defined as the sum of industry profits and consumer surplus, writes as follows:

$$
S W(t)=\sum_{i=1}^{N} \pi_{i}(t)+\frac{Q^{2}(t)}{2}-\varepsilon Q(t)-\gamma \frac{S^{2}(t)}{2},
$$

where

$$
\pi_{i}(t)=[p(t)-c] q_{i}(t)
$$

is firm $i$ 's instantaneous profit function.

In the remainder of the paper, we investigate three cases: (i) the non-cooperative game where firms compete à la Cournot-Nash to maximise individual profits; (ii) the first best solution, where the industry is governed by a benevolent planner aiming at the maximization of social welfare; (iii) a mixed oligopoly game where $K$ firms are public (and maximise social welfare), while the remaining $N-K$ are profit-seeking units. In case (i), firm $i$ chooses $q_{i}(t)$ to maximise the discounted individual profit flow:

$$
J_{i}^{C N}(t)=\int_{0}^{\infty} \pi_{i}(t) e^{-\rho t} d t
$$

s.t. the state dynamics (2) and the initial condition $S(0)=S_{0}$. Superscript $C N$ stands for Cournot-Nash. Parameter $\rho>0$ represents the constant discount factor common to all firms in the industry. In case (ii), which we will refer to as social planning (using superscript $S P$ ), the aggregate production level is chosen so as to maximise the discounted flow of social welfare:

$$
J^{S P}(t)=\int_{0}^{\infty}[S W(t)-X] e^{-\rho t} d t
$$


under the same constraints. The parameter $X \geq 0$ summarises the $\mathrm{X}$-inefficiency costs, paid in every instant $t$, possibly entailed by the lack of appropriate market incentives affecting the public firm. In case (iii), every public firm $k=1,2,3, \ldots, K$ maximises

$$
J_{k}^{M}(t)=\int_{0}^{\infty}[S W(t)-K X] e^{-\rho t} d t,
$$

where (9) takes into account the presence of $K$ sources of X-inefficiency, while every private firm $i=K+1, K+2, \ldots, N$ maximises (7) under constraint (2) and the initial condition.

\section{The Cournot-Nash game among profit-seeking firms}

Here we characterise the equilibrium of the first game, where all firms are private and compete à la Cournot-Nash to maximise individual profits. We consider the openloop Nash equilibrium, and show that the optimal output of firm $i$ never depends on the stock of pollution because firms are completely uninterested in the externality they produce.

Consider the current value Hamiltonian of firm $i$ :

$$
\mathcal{H}_{i}(t)=\pi_{i}(t)+\lambda_{i}(t) \dot{S}(t)
$$

The necessary conditions are as follows:

$$
\begin{gathered}
\frac{\partial \mathcal{H}_{i}}{\partial q_{i}}=a-c-2 q_{i}(t)-Q_{-i}(t)+\lambda_{i}(t)=0 \\
-\frac{\partial \mathcal{H}_{i}}{\partial S}=\dot{\lambda}_{i}(t)-\rho \lambda_{i}(t) \Leftrightarrow \dot{\lambda}_{i}(t)=(\rho+\delta) \lambda_{i}(t)
\end{gathered}
$$

with the transversality condition being:

$$
\lim _{t \rightarrow+\infty} e^{-\rho t} \lambda_{i}(t) S(t)=0
$$

Solving (12) yields:

$$
\lambda_{i}(t)=\lambda_{i}(0) e^{(\rho+\delta) t}
$$

Plugging (14) into (13), one obtains that the transversality condition holds if and only if $\lambda_{i}(0)=0$, i.e. for the trivial solution of (12). This leads the Cournot-Nash differential game to collapse into the static one, whereby the optimal output of firm 
$i$ is constant over time and coincides with the symmetric Cournot-Nash equilibrium of the static game

$$
q^{C N}(t)=\frac{a-c}{N+1}
$$

for all $t$. This can be ascertained by differentiating (11) w.r.t. time, imposing symmetry across quantities $\left(q_{i}(t)=q(t)\right.$ for all $\left.i\right)$ and using (12). Then the following control equation obtains:

$$
\dot{q}(t)=\frac{(\rho+\delta)[q(t)(N+1)-a+c]}{N+1} .
$$

The unique solution of (16) is (15). Intuitively, as the private firms do not internalize the effect of their production on the stock of pollution, they play the static solution of the Cournot-Nash game irrespective of $S .^{2}$ The associated profits and total output are, respectively,

$$
\begin{aligned}
\pi^{C N}(t) & =\left(\frac{a-c}{N+1}\right)^{2}, \\
Q^{C N}(t) & =\frac{N(a-c)}{N+1} .
\end{aligned}
$$

for all $t$ and all $S$. In the Cournot-Nash game, the stock of pollution never vanishes: it evolves over time as follows

$$
S(t)=\left(S(0)-\frac{N(a-c)}{\delta(N+1)}\right) e^{-\delta t}+\frac{N(a-c)}{\delta(N+1)}
$$

until the steady state stock of pollution $S^{C N}$ is reached,

$$
S^{C N}=\frac{N(a-c)}{\delta(N+1)}
$$

The associated steady state social welfare is

$$
S W^{C N}=\frac{N(a-c)}{2 \delta^{2}(N+1)^{2}}\left\{(a-c)\left[\delta^{2}(N+2)-\gamma N\right]-2 \delta^{2} \varepsilon(N+1)\right\} .
$$

Before proceeding to analyse the social optimum, we briefly evaluate the stability properties of the dynamic system (2)-(16), by looking at the associated Jacobian matrix:

$$
J=\left[\begin{array}{cc}
-\delta & N \\
0 & \rho+\delta
\end{array}\right],
$$

\footnotetext{
${ }^{2}$ One can equivalently show that the open-loop Nash equilibrium is a degenerate Markov Perfect Nash equilibrium where $q^{C N}(S)=(a-c) /(N+1)$ for all $S$.
} 
whose trace and determinant are

$$
\operatorname{Tr}(J)=\rho>0 ; \Delta(J)=-\delta(\rho+\delta)<0 .
$$

Accordingly,

Proposition 1 The Cournot-Nash equilibrium of the differential game is a saddle point.

\section{The social optimum}

Here we assess the first best equilibrium where the industry is controlled by a benevolent planner choosing the output level so as to maximise social welfare. Given that production takes place at CRS, we can simplify the model assuming that the planner concentrates production in a single public firm, whose Bellman equation is:

$$
\rho V_{S P}(S)=\max _{Q_{S P}}\left[S W-X+\frac{\partial V_{S P}(S)}{\partial S}\left(Q_{S P}-\delta S\right)\right]
$$

where the subscript $S P$ stands for social planner. Note that the objective function of the public firm includes both social welfare and the X-inefficiency. In view of the fact that social welfare contains a quadratic externality, the problem takes a linear-quadratic structure and therefore we set $V_{S P}(S)=\varphi_{1}+\varphi_{2} S+\varphi_{3} S^{2}$. The first order condition (FOC) is:

$$
Q_{S P}=a-c-\varepsilon+\varphi_{2}+2 \varphi_{3} S
$$

Plugging (25) into (24) yields

$$
\Omega\left(\varphi_{1}, \varphi_{2}\right)+\Psi\left(\varphi_{2}, \varphi_{3}\right) S+\Phi\left(\varphi_{3}\right) S^{2}=0
$$

where $\Omega\left(\varphi_{1}, \varphi_{2}\right), \Psi\left(\varphi_{2}, \varphi_{3}\right)$ and $\Phi\left(\varphi_{3}\right)$ must simultaneously be equal to zero w.r.t. $\varphi_{1}, \varphi_{2}$ and $\varphi_{3}$. This yields the values for $\varphi_{1}, \varphi_{2}$ and $\varphi_{3}$ (see the Appendix for the exact values). Substituting in (25) and solving, we obtain that the policy function of the single public firm is a decreasing function of the current amount of pollution (Benchekroun and Long, 1998)

$$
Q_{S P}(S)=\frac{2(a-c-\varepsilon)(\delta+\rho)}{\rho+z}-\frac{z-2 \delta+\rho}{2} S,
$$


where $z=\sqrt{4 \gamma+(2 \delta+\rho)^{2}}$. Note that, as the X-inefficiency only affects the level of net social welfare, it does not affect the optimal output (27) along the optimal path. It does affect, however, the social planner's optimal value function (through the parameter $\left.\varphi_{1}\right)$ :

$$
\begin{aligned}
V_{S P}(S)= & \frac{2(a-c-\varepsilon)^{2}(\delta+\rho)^{2}}{\rho(\rho+z)}-\frac{X}{\rho} \\
& +\frac{(a-c-\varepsilon)(2 \delta+\rho-z)^{2}}{\rho+z} S+\frac{1}{4}(2 \delta+\rho-z) S^{2} .
\end{aligned}
$$

For later reference, note that the discounted social welfare $W_{S P}(S)$, excluding the (discounted) X-inefficiency of running one public firm, is

$$
W_{S P}(S)=V_{S P}(S)+\frac{X}{\rho}
$$

Imposing stationarity, the steady state output, stock of pollution and social welfare (excluding the X-inefficiency cost) read as follows:

$$
\begin{aligned}
S_{S P}^{*} & =\frac{(a-c-\varepsilon)(\rho+\delta)}{\delta(\rho+\delta)+\gamma}, \\
Q_{S P}^{*} & =\frac{(a-c-\varepsilon)(\rho+\delta) \delta}{\delta(\rho+\delta)+\gamma} \\
S W_{S P}^{*} & =(a-c-\varepsilon)^{2}(\rho+\delta) \frac{\delta^{2}(\rho+\delta)-\gamma(\rho-\delta)}{2[\delta(\rho+\delta)+\gamma]^{2}} .
\end{aligned}
$$

\section{Cournot-Nash equilibrium vs. social planning}

Leaving aside $X$, intuitively, $S W_{S P}^{*}>S W^{C N}$. Therefore, if $S W_{S P}^{*}-S W^{C N}>X$, the overall welfare appraisal speaks in favour of public monopoly. However, a priori it is not clear whether $S^{C N}<S_{S P}^{*}$ and $Q^{C N}<Q_{S P}^{*}$. The reason is that, in deciding how much to produce, the planner faces a tradeoff between expanding output to increase consumer surplus via a price reduction or decreasing it to reduce the environmental externality. To shed some light on this issue we will focus on the comparison between $S_{S P}^{*}$ and $S^{C N}$. First, note that

$$
S^{C N}-S_{S P}^{*}=\frac{1}{\delta}\left[\varepsilon+\frac{(a-c-\varepsilon) \gamma}{\gamma+\delta(\delta+\rho)}-\frac{a-c}{1+N}\right]
$$

with the following comparative static properties

$$
\frac{\partial\left(S^{C N}-S_{S P}^{*}\right)}{\partial N}>0 .
$$


Second, $S^{C N}>S_{S P}^{*}$ for all

$$
N>\tilde{N}=\delta(\rho+\delta) \frac{a-c-\varepsilon}{\gamma(a-c)+\delta(\rho+\delta) \varepsilon} .
$$

or, equivalently,

$$
\gamma>\tilde{\gamma}=\frac{\delta(\rho+\delta)(a-c-\varepsilon)}{N(a-c)}-\frac{\varepsilon}{a-c} .
$$

Proposition 2 If the number of firms in the industry is sufficiently large, $N>\tilde{N}$, or equivalently, if the weight $\gamma$ given to the environmental externality is sufficiently high, $\gamma>\tilde{\gamma}$, the steady state output and stock of pollution of the Cournot-Nash game are higher than is socially optimal: $Q^{C N}>Q_{S P}^{*}$ and $S^{C N}>S_{S P}^{*}$.

Therefore, if the external effect is a major one, then the planner finds it optimal to produce less than the firms do at the Cournot-Nash equilibrium, because the tradeoff speaks in favour of an output contraction, the price effect being more than offset by the decrease in pollution.

\section{The mixed market}

We now consider a mixed market where some firms are public, while the remaining ones are profit-seekers. We will show that, despite the fact that the stock of pollution does not directly affect the instantaneous profit function of private firms, it nevertheless indirectly affects the strategic choices of profit-seeking firms because of the market interaction with the public firms. Notably, this drives the whole industry along the same optimal path and steady state that would be optimal under social planning.. In other words, the evolution of aggregate output, stock of pollution and social welfare in the mixed market exactly reproduces the first best solution.

As for the solution under social planning, we focus on the Markov Perfect Nash equilibrium. Let the value function of a public firm $k=1,2, \ldots, K$ and that of a private firm $i=K+1, K+2, \ldots, N$ be, respectively

$$
\begin{aligned}
& V_{k}^{M}(S)=\eta_{1}+\eta_{2} S+\eta_{3} S^{2} \\
& V_{i}^{M}(S)=\nu_{1}+\nu_{2} S+\nu_{3} S^{2}
\end{aligned}
$$

where the superscript $M$ stands for mixed. The Bellman equations of a public and 
a private firm read as follows:

$$
\begin{aligned}
\rho V_{k}^{M}(S) & =\max _{q_{k}}\left\{S W-K X+\frac{\partial V_{k}^{M}(S)}{\partial S}(Q-\delta S)\right\}, \\
\rho V_{i}^{M}(S) & =\max _{q_{i}}\left\{\pi_{i}+\frac{\partial V_{i}^{M}(S)}{\partial S}(Q-\delta S)\right\} .
\end{aligned}
$$

Taking the derivative of (39) and (40) w.r.t. $q_{k}$ and $q_{i}$, respectively, and solving allows obtaining the policy function chosen by each firm as a function of the the other firms' output and of the stock of pollution:

$$
\begin{aligned}
q_{k}^{M} & =a-c-\varepsilon+\eta_{2}-q_{i}-Q_{-i}-Q_{-k}+2 \eta_{3} S \\
q_{i}^{M} & =\frac{1}{2}\left(a-c+\nu_{2}-q_{k}-Q_{-i}-Q_{-k}\right)+v_{3} S
\end{aligned}
$$

where $Q_{-i}$ is the total production of the private firms, excluding firm $i$, and $Q_{-k}$ is the total production of the public firms, excluding firm $k$, i.e. $q_{i}+q_{k}+Q_{-i}+Q_{-k}=Q$.

As expected in a market where firms compete à la Cournot, the optimal ouput chosen by each firm is a decreasing function of the other firms' output. Public firms, however, are twice more reactive than profit-seeking firms than the profitsseeking firms, and react in a one-to-one proportion to the output of the other firms. Moreover, it is important to stress that, in the mixed market, it is no longer true that the generic profit-seeking firm $i$ ignores the externality $S$ (see eq. 42). The reason is that reaction functions depend on aggregate production, which is affected by the amount of pollution $S$ because public firms have objective functions that explicitly depend on it. Therefore, even though private firms's profits are not directly affected by $S$, they are indirectly affected by $S$ through strategic interaction on the market.

Assuming that all public and private firms choose symmetrically, i.e. $q_{k}+Q_{-k}=$ $K q_{k}$ and $q_{i}+Q_{-i}=(N-K) q_{i}$, and solving with respect to $q_{k}$ and $q_{i}$ yields the following policy functions,

$$
\begin{aligned}
q_{k}^{M}(S)= & \frac{a-c-(N-K) \nu_{2}-(N-K+1)\left(\varepsilon-\eta_{2}\right)}{K} \\
& -2 \frac{(N-K) \nu_{3}-(N-K+1) \eta_{3}}{K} S, \\
q_{i}^{M}(S)= & \varepsilon+\nu_{2}-\eta_{2}+2\left(\nu_{3}-\eta_{3}\right) S .
\end{aligned}
$$

Note that the optimal output of the private firms does not depend on the industry concentration, nor on the number of public firms. Due to the market interaction with the public firms, now the private firms make output choices conditional only on 
the stock of pollution. On the contrary, the productive choices of the public firms also take into account the market concentration and the number of private firms. The total output is

$$
\begin{aligned}
Q^{M}(S) & =K q_{k}+(N-K) q_{i} \\
& =a-c+\eta_{2}+2 \eta_{3} S .
\end{aligned}
$$

Interestingly, (46) does not depend on $N$ and $K$, nor on the parameters characterising the value functions of the private firms: only the parameters appearing in the value function of the public firms are relevant in determining the total industry output and the corresponding evolution of the stock of pollution.

We can now simplify the Bellman equations (39) and (40) for public and private firms, respectively, as follows

$$
\begin{aligned}
\Gamma\left(\eta_{1}, \eta_{2}\right)+\Delta\left(\eta_{2}, \eta_{3}\right) S+\Lambda\left(\eta_{3}\right) S^{2} & =0 \\
\Xi\left(\nu_{1}, \nu_{2}, \eta_{2}\right)+\Upsilon\left(\nu_{2}, \nu_{3}, \eta_{2}, \eta_{3}\right) S+\digamma\left(\nu_{3}, \eta_{3}\right) S^{2} & =0 .
\end{aligned}
$$

Solving $\Gamma\left(\eta_{1}, \eta_{2}\right)=\Delta\left(\eta_{2}, \eta_{3}\right)=\Lambda\left(\eta_{3}\right)=0$ and $\Xi\left(\nu_{1}, \nu_{2}, \eta_{2}\right)=\Upsilon\left(\nu_{2}, \nu_{3}, \eta_{2}, \eta_{3}\right)=$ $\digamma\left(\nu_{3}, \eta_{3}\right)=0$, yields the values of the coefficients $\eta_{1}, \eta_{2}, \eta_{2}, \nu_{1}, \nu_{2}$ and $\nu_{3}$ (see the Appendix for the exact values). Note that the parameters $\eta_{2}, \eta_{3}$ that characterize the value function $V_{k}^{M}(S)$ of a public firm in the mixed market are the same as those that characterize the value function $V_{S P}(S)$ of the public firm under social planning. As the parameter $\eta_{1}$ takes into account the X-inefficiency entailed by the public firms, it coincides with $\varphi_{1}$ only if $K=1$, i.e. if the mixed market contains a single public firm.

Plugging in the values $\nu_{1}, \nu_{2}, \nu_{3}, \eta_{1}, \eta_{2}$ and $\eta_{3}$ in (46), one obtains that the total output in the mixed market coincides with the total output under social planning,

$$
Q^{M}(S)=Q_{S P}(S)
$$

for all $S$. Given that the environmental externality is a linear function of the industry output, also the evolution of the stock of pollution and social welfare coincides with the first best solution. Moreover, given that firms' profits are linear in the output, also industry profits in the mixed market coincide with the first best. We are now ready to state the main result of the paper.

Proposition 3 In the mixed market: 
1. along the optimal path, the industry output, industry profits and social welfare are the same as under social planning for all levels of pollution $S$,

2. the evolution of pollution is the same as under social planning,

3. in steady state, the stock of pollution, the industry output, the industry profits and social welfare are the same as under social planning.

It is instructive to consider what are the production levels of the private and public firms along the optimal path leading to the steady state. Note first that $\eta_{3}<\nu_{3}<0$, which implies that the optimal output (45) is increasing in the stock of pollution for the private firms, and decreasing for the public ones (eq. 43). Overall, however, the total industry output (46) is decreasing in the stock of pollution (as it is under social planning). ${ }^{3}$ Second, as $\varepsilon+\nu_{2}-\eta_{2}>0$, the optimal output produced by a private firm is always positive. The industry output, and the output produced by a public firm, however, can be negative for large enough stocks of pollution. Let $z=\sqrt{4 \gamma+(2 \delta+\rho)^{2}}$ and define $\hat{S}$ as the threshold stock of pollution below which the industry output along the optimal path is positive,

$$
\begin{aligned}
\hat{S} & =\frac{4(\delta+\rho)(a-c-\varepsilon)}{(z+\rho)(z-2 \delta-\rho)} \\
& <S^{M *}=S_{S P}^{*} .
\end{aligned}
$$

When describing the setup in Section 2, we assumed that the stock of pollution $S$ is always below such a level. This does not guarantee, however, that the output of a public firm is always positive, as it also depends on the market concentration (see eq. 45). The condition for the output of a public firm to be positive all along the optimal path is that both the initial and terminal production levels are positive, i.e. $q_{k}\left(S_{0}\right) \geq 0$ and $q_{k}\left(S^{M *}\right) \geq 0$. This is equivalent to requiring

$$
\begin{aligned}
S_{0} & \leq \bar{S}(K), \\
S^{M *} & \leq \bar{S}(K),
\end{aligned}
$$

where

$$
\bar{S}(K)=\frac{1}{2} \frac{a-c-\nu_{2}(N-K)-\left(\varepsilon-\eta_{2}\right)(N-K+1)}{\nu_{3}(N-K)-\eta_{3}(N-K+1)} \leq \hat{S}(K)
$$

is the threshold stock of pollution below which the public firm's output is positive. When the above conditions hold, the mixed market where private and public firms

\footnotetext{
${ }^{3}$ Convergence to the steady state is guaranteed by the fact that $\eta_{3}<0<\delta$.
} 
coexist will follow the first best optimal path. If instead this were not the case, one might exploit the fact that $\partial \bar{S}(K) / \partial K>0$ and $\lim _{K \rightarrow N} \bar{S}(K)=\hat{S}(K)$, and consider a mixed market where the number of public firms is large enough to ensure that $\bar{S}(K)$ satisfies both (52) and (53).

Proposition 4 For a given stock of pollution $S_{0}$, in the mixed market there exists a number $K^{*} \in[1, N]$ of public firms such that, for all $K \geq K^{*}$ :

1. all private and public firms have positive productions levels along the optimal path,

2. the industry output, the stock of pollution and social welfare coincide with the first best outcome both along the optimal path and in steady state.

The above proposition states that there exists a minimum number of public firms such that the mixed market is able to reproduce the first best outcome. Such a minimum number could be just one, provided that

$$
\begin{aligned}
S_{0} & \leq \bar{S}(1) \\
S^{M *} & \leq \bar{S}(1) .
\end{aligned}
$$

As an example, consider the case where (i) the industry is at the steady state of the Cournot-Nash game among profit-seeking firms, $S_{0}=S^{C N}$, and (ii) the CournotNash outcome is associated to more production and pollution than would be socially desirable in steady state: $S^{M *}<S^{C N}$. From Proposition 2 we know that the latter case occurs if $N>\tilde{N}$. Define $\hat{N}$ as the number of firms such that $S^{C N}=\bar{S}(1)$, then the following holds

Proposition 5 Suppose the market is in the Cournot-Nash steady state. If there exists an integer number $N$ such that $N \in(\max \{2, \tilde{N}\}, \hat{N}]$, one public firm suffices to regulate the market and drive it along the optimal path to the first best outcome.

See the Appendix for the proof. Given specific values for the parameters, it is possible to verify whether the number of firms in the industry satisfies the above requirements. For instance, consider the case where $a=10, c=0, \rho=1 / 20$, $\delta=2 / 5, \varepsilon=1 / 10, \gamma=1 / 10$. Then $\tilde{N}=1.75$, and $\hat{N}=2.1$. Hence, if $N=2$, Proposition 5 holds and having a single public firm suffices to yield the first best. 


\section{Regulating the market using public firms}

In the previous section we have shown that a mixed market suffices to regulate production and pollution according to the first best solution. While this regulating task is a possible option, it might not be a desirable option if the associated costs more than offset the benefits. In this section we explicitly consider these costs and benefits, and we show the conditions under which creating a mixed market is desirable.

For concreteness, consider the case where the the Cournot-Nash game among $N$ profit-seeking firms is at the steady state and the social planner is contemplating the possibility of buying $K \geq K^{*}$ firms out of the $N$ profit-seeking firms populating the market. For any given stock of pollution $S$, the regulation of the market via public firms is desirable if and only if the discounted stream of social welfare of the mixed market $W^{M}$, minus the $\mathrm{X}$-inefficiency costs and the acquisition cost $\beta$ of each private firm, is larger than discounted stream of social welfare under the Cournot-Nash game $W^{C N}$ :

$$
W^{M}(S)-\left(\frac{X}{\rho}-B\right) K>W^{C N}(S) .
$$

In the case under consideration, the initial stock of pollution is $S_{0}=S^{C N}$ because the economy is in the Cournot-Nash steady state. In such a case the discounted social welfare associated to the Cournot-Nash game is computed from (21) as follows

$$
W^{C N}\left(S^{C N}\right)=\frac{1}{\rho} S W^{C N}
$$

Firms are bought at market price. Assume that the acquisition $\operatorname{cost} \beta$ of each profitseeking firm is equal to the present value of the discounted profits accruing to firm $i$ (eq. 17),

$$
\beta=\frac{1}{\rho} \pi^{C N}=\frac{(a-c)^{2}}{\rho(n+1)^{2}},
$$

To compute $W^{M}(S)$ we can use the fact that, for every $S$, social welfare is the same under social planning and in the mixed market (Proposition 3). For a generic $S$, this implies $W^{M}(S)=W_{S P}(S)$ and, in the case under consideration,

$$
W^{M}\left(S^{C N}\right)=W_{S P}\left(S^{C N}\right) .
$$

Substituting in (57) yields the following (see the Appendix for the exact value of $\left.X^{*}\right)$ : 
Proposition 6 There exists a threshold level of $X$-inefficiency $X^{*}$ such that, if $X<X^{*}$, it is socially desirable to nationalize $K$ private firms and drive the industry steady state output, stock of pollution and social welfare to the first best outcome.

Even when the cost of buying and running the public firms are taken into account, there are conditions under which creating a mixed market is welfare improving and allows regulating a Cournot oligopoly where production takes place at constant returns to scale and entails a negative environmental externality. As a final remark, it is worth mentioning that we have implicitly assumed that the market concentration remains constant. In other words, we have considered the case where all $K$ firms must produce after being nationalised. Without this requirement, the social planner might exploit the linear technology, and concentrate the production of $K$ public firms in a single (big) public firm to save on the X-inefficiency costs associated to running the remaining $K-1$ public firms. Clearly, this implies that the requirement indicated in Proposition 6 would become less stringent.

\section{Conclusions}

We have addressed the issue of regulating pollution using public firms as a tool for finely-tuning the industry output. In principle, modifying the overall amount of production in an industry with polluting emissions has two opposite effects: one is the classical price effect, the other is the external effect, that is, any output expansion has the welcome effect of reducing price, but the undesirable effect of increasing polluting emissions.

Indeed, the foregoing analysis has shown that industry output at the social planning equilibrium may be lower than the Cournot-Nash industry output if the number of firms is sufficiently large. In this respect we have identified sufficient conditions on the parameters such that, if the weight attached to the external effect is high enough, then the planner would always shrink production as compared to the Cournot-Nash equilibrium. Then we have shown that in a mixed market it is possible to obtain the same output and welfare, and the same evolution for the stock of pollution, as under social planning. This outcome is due to the fact that, although the environmental externality does not directly affect private firms's profits, it does so indirectly through market interaction because the public firms do include the external effect into account. Interestingly, there exist conditions under which a single public firm suffices to perform such a regulating action. 
Public firms might however lack the appropriate market incentives to be as efficient as private firms. We ackwnowledge this issue, and we allow public firms to incur some X-inefficiency costs at each point in time. Even when taking Xinefficiency costs into account, it may be socially convenient for the social planner to buy some profit-seeking firms at market prices and substitute them with public firms. We conclude that the creation of a mixed market candidates as an alternative policy tool for the regulation of externalities with respect to using Pigouvian taxation or the efficient allocation of polluting rights. The feasibility of regulating environmental externalities via public firms in industries where the technology features either increasing or decreasing returns to scale remains to be investigated. This extension is left for future research. 


\section{References}

[1] Bartz, S. and D.L. Kelly (2008). Economic growth and the environment: theory and facts. Resource and Energy Economics, 30, 115-149.

[2] Benchekroun, H. and N.V. Long (1998). Efficiency inducing taxation for polluting oligopolists. Journal of Public Economics, 70, 325-342.

[3] Benchekroun, H. and N.V. Long (2002). On the multiplicity of efficiencyinducing tax rules. Economics Letters, 76, 331-336.

[4] Bergstrom, T., J. Cross and R. Porter (1987). Efficiency-inducing taxation for a monopolistically supplied depletable resource. Journal of Public Economics, 15, 23-32.

[5] Chiou, J.-R. and J.-L. Hu (2001). Environmental research joint ventures under emission taxes. Environmental and Resource Economics, 21, 129-46.

[6] Cremer, H., M. Marchand and J.-F. Thisse (1989). The public firm as an instrument for regulating an oligopolistic market. Oxford Economic Papers, 41, 283-301.

[7] Cremer, H., M. Marchand and J.-F. Thisse (1991). Mixed oligopoly with differentiated products, International Journal of Industrial Organization, 9, 43-53.

[8] Damania, D. (1996). Pollution taxes and pollution abatement in an oligopoly supergame. Journal of Environmental Economics and Management, 30, 323-36.

[9] De Fraja, G. and F. Delbono (1989). Alternative strategies of a public enterprise in oligopoly. Oxford Economic Papers, 41, 302-11.

[10] De Fraja, G. and F. Delbono (1990). Game theoretic models of mixed oligopoly, Journal of Economic Surveys, 4, 1-17.

[11] Downing, P.B. and L.J. White (1986). Innovation in pollution control. Journal of Environmental Economics and Management, 8, 225-71.

[12] Greiner, A. (2007). The dynamic behaviour of an endogenous growth model with public capital and pollution. Studies in Nonlinear Dynamics and Econometrics, 11, 1-9. 
[13] Hartman, R. and O.S. Kwon (2005). Sustainable growth and the environmental Kuznets curve. Journal of Economic Dynamics and Control, 29, 1701-1736.

[14] Itaya, J. (2008). Can environmental taxation stimulate growth? The role of indeterminacy in endogenous growth models with environmental externalities. Journal of Economic Dynamics and Control, 32, 1156-1180.

[15] Karp, L. and J. Livernois (1992). On efficiency-inducing taxation for a nonrenewable resource monopolist. Journal of Public Economics, 49, 219-239.

[16] Karp, L. and J. Livernois (1994). Using automatic tax changes to control pollution emissions. Journal of Environmental Economics and Management, 27, 38-48.

[17] Lambertini, L. and A. Mantovani (2008). Collusion helps abate environmental pollution: a dynamic approach. In M. J. Chung, P. Misra and H. Shim (eds), Preprints of the 17th IFAC World Congress (Seoul, Korea, July 6-11 2008), IFAC (in CD-rom).

[18] Leinbenstein, H. (1966). Allocative efficiency versus X-efficiency. American Economic Review, 56, 392-415.

[19] Milliman, S.R. and R. Prince (1989). Firm incentives to promote technological change in pollution control. Journal of Environmental Economics and Management, 17, 247-65.

[20] Newbery, D. (1990). Acid rain. Economic Policy, 11, 298-346.

[21] Tsur, Y. and A. Zemel (2002). The regulation of environmental innovations. Journal of Environmental Economics and Management, 44, 242-60.

[22] Tsur, Y. and A. Zemel (2008). Regulating environmental threats. Environmental and Resource Economics, 39, 297-310.

[23] von der Fehr, N.-H. (1993). Tradeable emission rights and strategic interaction. Environmental and Resource Economics, 3, 129-151. 


\section{Appendix}

Parameters of the value function under social planning

Let $z=\sqrt{4 \gamma+(2 \delta+\rho)^{2}}$, then the parameters of the value function $V_{S P}(S)=$ $\varphi_{1}+\varphi_{2} S+\varphi_{3} S^{2}$ are as follows

$$
\begin{aligned}
\varphi_{1} & =\frac{(a-c-\varepsilon)(2 \delta+\rho-z)}{\rho+z}-\frac{X}{\rho} \\
\varphi_{2} & =\frac{(a-c-\varepsilon)(2 \delta+\rho-z)}{\rho+z} \\
\varphi_{3} & =\frac{2 \delta+\rho \pm z}{4}
\end{aligned}
$$

The negative root of $\varphi_{3}$ is chosen to ensure concavity of the value function.

Parameters of the value functions of public and private firms in the mixed market

The parameters of the value function $V_{j}^{M}(S)=\eta_{1}+\eta_{2} S+\eta_{3} S^{2}$ of each public firm are as follows:

$$
\begin{aligned}
& \eta_{1}=\frac{(a-c-\varepsilon)(2 \delta+\rho-z)}{\rho+z}-K \frac{X}{\rho}, \\
& \eta_{2}=\varphi_{2}, \\
& \eta_{3}=\varphi_{3} .
\end{aligned}
$$

The parameters of the value function $V_{i}^{M}(S)=\nu_{1}+\nu_{2} S+\nu_{3} S^{2}$ of the profit-seeking firms are as follows:

$$
\begin{aligned}
\nu_{1}= & \frac{1}{\rho}\left[\left(\frac{(a-c-\varepsilon)(2 \delta+\rho-z)}{\rho+z}-\varepsilon\right)^{2}\right. \\
& +\frac{2(a-c)}{\delta+\rho}\left(\frac{(a-c)(2 \delta+\rho-z)^{2}}{4(2 \delta+\rho)}+\frac{(a-c-\varepsilon)(2 \delta+\rho-z)^{2}}{2(\rho+z)}-\frac{\varepsilon(2 \delta+\rho-z)}{2}(\oint J)\right. \\
\nu_{2}= & \frac{2}{\delta+\rho}\left[\frac{(a-c)(2 \delta+\rho-z)^{2}}{4(2 \delta+\rho)}+\frac{(a-c-\varepsilon)(2 \delta+\rho-z)^{2}}{2(\rho+z)}-\frac{\varepsilon(2 \delta+\rho-z)}{2}\right] \\
\nu_{3}= & \frac{(2 \delta+\rho-z)^{2}}{4(2 \delta+\rho)}
\end{aligned}
$$

Given $S^{M *}<S^{C N}=S_{0}$, a single public firm suffices to regulate the mixed market 
We are considering the case where the Cournot-Nash pollution is larger than the first best pollution:

$$
S_{S P}^{*}=S^{M *}<S^{C N}=S_{0} .
$$

According to Proposition 3, this occurs if $N>\tilde{N}$.

The conditions to guarantee that one firm suffices to regulate the mixed market are as follows

$$
\begin{aligned}
S_{0} & \leq \bar{S}(1), \\
S^{M *} & <\bar{S}(1) .
\end{aligned}
$$

Thus we have to find the conditions under which

$$
\begin{aligned}
S^{C N} & \leq \bar{S}(1), \\
N & >\tilde{N} .
\end{aligned}
$$

Condition (73) is satisfied if

$$
A N^{2}+B N+C \geq 0
$$

where

$$
\begin{gathered}
A=2(2 \delta+\rho)[(a-c) \gamma+\delta \varepsilon(\delta+\rho)](\delta-z)<0, \\
B=\quad 2(a-c)(\delta+\rho)\left(2 \delta^{2}+\gamma+\delta \rho\right) z-2(\delta+\rho)\{4(a-c) \delta \gamma \\
\left.+\delta \varepsilon(\delta+\rho)(2 \delta+\rho)+(a-c)\left[2 \delta^{3}+\left(\delta^{2}+\gamma\right) \rho\right]\right\}>0, \\
C=\quad \delta\left[2(a-c) \gamma \rho-2 \varepsilon(\delta+\rho)(2 \delta+\rho)^{2}+(a-c)(\delta+\rho)(2 \delta+\rho)(4 \delta+3 \rho)\right] \\
+2 \delta z\left[2(a-c) \gamma-(a-c-2 \varepsilon)\left(2 \delta^{2}+3 \delta+{ }^{2} \rho\right)\right]>0 .
\end{gathered}
$$

Given that $C$ is positive, $(75)$ is satisfied for $N \in(0, \hat{N}]$, where $\hat{N}$ is the positive root of the parabola (75).

To sum up, Proposition 6 holds if there exists an integer number $N$ such that the following conditions are met:

1. $N \geq 2$,

2. $N>\tilde{N}$ (the Cournot-Nash output is larger than the first best output), 
3. $N \leq \hat{N}$ (the initial output is non negative).

\section{Critical X-inefficiency cost}

The condition for the desirability of a mixed market with respect to a CournotNash oligopoly at the steady state is

$$
W^{M}\left(S^{C N}\right)-K^{*} \frac{X}{\rho}-K^{*} \beta>W^{C N}\left(S^{C N}\right),
$$

where

$$
\begin{gathered}
W^{C N}\left(S^{C N}\right)=\frac{(a-c) N\left(2 \delta^{2}(a-c-\varepsilon)+\left(\delta^{2}(a-c-2 \varepsilon)+(-a+c) \gamma\right) N\right)}{2 \delta^{2}(1+N)^{2} \rho} \\
\beta=\frac{(a-c)^{2}}{\rho(1+N)^{2}} \\
W^{M}\left(S^{C N}\right)=\frac{(a-c)^{2} N^{2}(2 \delta+\rho-z)}{4 \delta^{2}(1+N)^{2}}+\frac{2(a-c-\varepsilon)^{2}(\delta+\rho)^{2}}{\rho(\rho+z)^{2}} \\
+\frac{(a-c)(a-c-\varepsilon) N(2 \delta+\rho-z)}{\delta(1+N)(\rho+z)}
\end{gathered}
$$

Substituting and solving in (76) yields the following critical inefficiency cost:

$$
\begin{aligned}
X^{*}= & \frac{(a-c)(a-c-\varepsilon) N \rho(z-\rho)}{\delta(1+N) K^{*}(\rho+z)}-\frac{(a-c)^{2}}{(1+N)^{2}} \\
& -\frac{2(a-c-\varepsilon)^{2}(\delta+\rho)^{2}}{K^{*}(\rho+z)^{2}}-\frac{2 N \rho(a-c)(a-c-\varepsilon)}{(1+N) K^{*}(\rho+z)} \\
& -\frac{(a-c) N[(a-c)(2+N)-2 \varepsilon(1+N)]}{2 K^{*}(1+N)^{2}} \\
& -\frac{(a-c)^{2} N^{2}\left(2 \gamma+2 \delta \rho+\rho^{2}-\rho z\right)}{4 K^{*} \delta^{2}(1+N)^{2}} .
\end{aligned}
$$




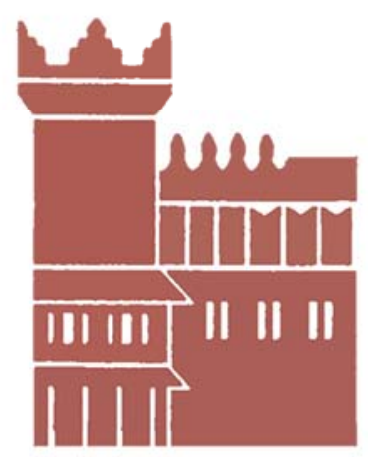

Alma Mater Studiorum - Università di Bologna DEPARTMENT OF ECONOMICS

Strada Maggiore 45

40125 Bologna - Italy

Tel. +39051 2092604

Fax +390512092664

http://www.dse.unibo.it 